\title{
Mujer con acúfeno pulsátil y soplo craneal
}

\author{
Woman with pulsatile tinnitus and cranial bruit
}

Mujer de 45 años, con antecedentes de trombosis en venas femoral común y poplítea izquierdas e hipertrigliceridemia. Remitida por cefalea crónica diaria de 7 meses de evolución, que definía como frontotemporal izquierda, de intensidad moderada, asociada a un acúfeno pulsátil continuo izquierdo. Presentaba exacerbaciones del dolor cuando realizaba maniobras de Valsalva. No asociaba fiebre, síndrome general, claudicación mandibular ni debilidad de cintura escapular. El dolor no la despertaba de noche, ni evidenciaba una preferencia circadiana.

En la exploración se apreciaba un notable soplo hemicraneal izquierdo de predominio mastoideo. La tomografía computarizada cerebral no evidenció patología. En la resonancia magnética cerebral (Figura 1) se observó un aumento de velocidad del flujo venoso en senos transverso (flecha gruesa) y sigmoide (flecha delgada) izquierdos en relación con una fístula dural. Obsérvese la aparente normalidad en la secuencia FLAIR (Figura 2), frente al elocuente hallazgo en TOF (Figura 1), secuencia rápida e inocua que no implica la administración de contraste. El estudio de la coagulación mostró heterocigosis para la mutación G1691A asociada al gen del Factor $V$ de Leiden, y una actividad aumentada de la proteína C (147\% [70 - 140]). Esto es congruente con una nueva trombosis, en este caso de senos venosos, como origen de la fístula. La cefalea se resolvió tras la embolización de la misma.

\section{Bibliografía}

1. Mossa-Basha M, Chen J, Gandhi D. Imaging of cerebral arteriovenous malformations and dural arteriovenous fistulas. Neurosurg Clin N Am. 2012; 23 (1):27-42.

2. Oh JT, Chung SY, Lanzino G, Park KS, Kim SM, Park MS, et al. Intracranial dural arteriovenous fistulas: clinical characteristics and management based on location and hemodynamics. J Cerebrovasc Endovasc Neurosurg. 2012 Sep; 14(3):192-202.

3. Sorkin GC, Hopkins LN. Endovascular role in dural arteriovenous fistula management. World Neurosurg. 2013; 80 (6):219-20.

\section{Diagnóstico: Fístula dural}

Juan Manuel Pías-Peleteiro, Jose Manuel Aldrey-Vázquez Servicio de Neuroloxía, Complexo Hospitalario Universitario de Santiago de Compostela (CHUS). SERGAS. A Coruña.
Figura 1. Resonancia nuclear magnética; secuencia TOF (Time of Flight)

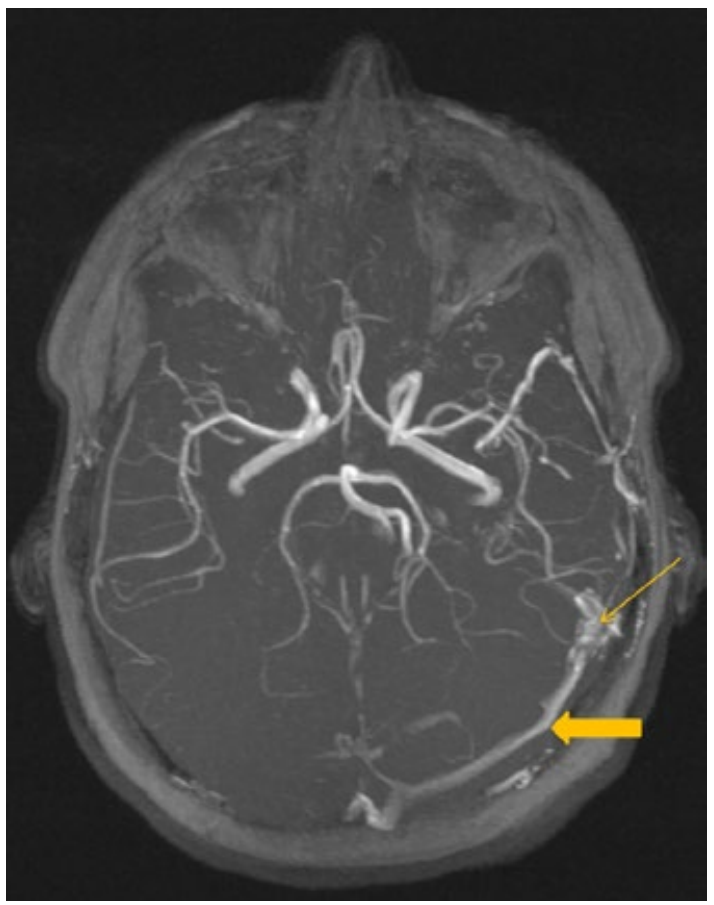

Figura 2. Resonancia nuclear magnética; secuencia FLAIR (Fluid Attenuated Inversion Recovery)

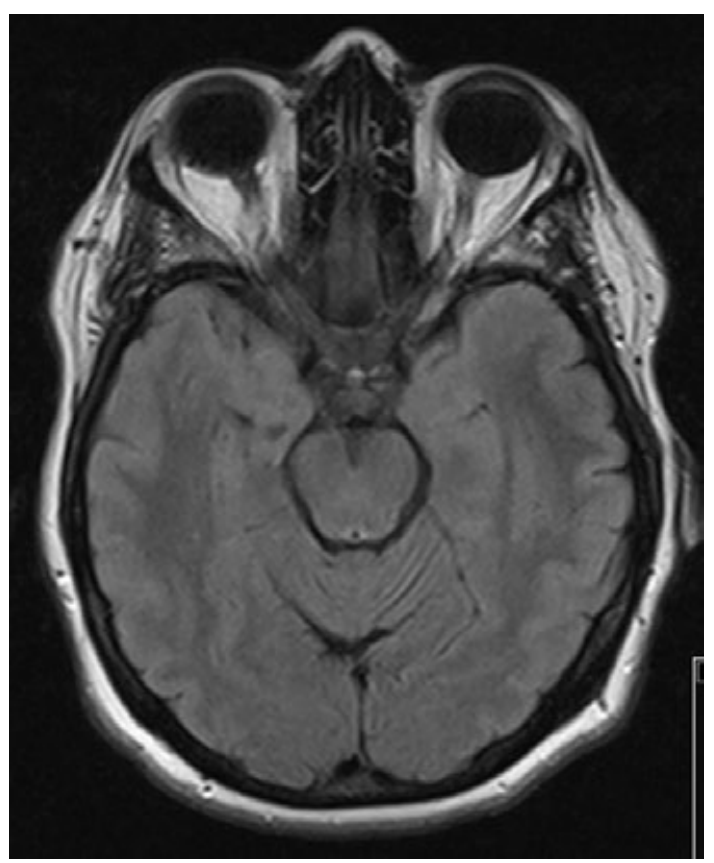

